\title{
ALPHA-BETA SEPARATION PORTFOLIO STRATEGIES FOR ISLAMIC FINANCE
}

\author{
Valentyn Khokhlov' \\ Global Spirits, Ukraine
}

\begin{abstract}
The purpose of this paper is to develop a mathematical alpha-beta separation model that can be used to create a core-satellite portfolio management strategy that complies with the principles of Islamic finance. Methodology. Core-satellite portfolio construction methodology is used to implement the alpha-beta separation approach, where the core part of the portfolio is managed using the tracking error minimization strategy, and the satellite part of the portfolio is managed using the mean-variance optimization strategy. Results of the portfolio dynamics clearly show that a significant amount of value was created by alpha-beta separation. The typical alpha ranges from $4 \%$ to $5.7 \%$. The most aggressive portfolio strategies that allow short positions in the satellite portfolio work best with frequent rebalancing and benefit from the active bets. Smoothing technique that was introduced to decrease the portfolio turnover and stabilize its composition works better when active bets are less efficient, particularly with less frequent rebalancing. The best risk-return combinations are achieved with modest (3\% to 10\%) allocation of the total portfolio to the satellite, and the remaining part ( $90 \%$ to $97 \%$ ) being managed in order to minimize the tracking error. Practical implications. The alpha-beta separation framework suggested in this paper can be used to enhance the portfolio management techniques for the hedge funds that operate under tight restrictions, particularly under the Islamic finance principles. The mathematical models developed in this paper allow practical implementation of the alphabeta separation concept. Originality/value. While the idea of alpha-beta separation existed in hedge fund management before, there was no comprehensive mathematical model under it, so its implementation was based on the ad hoc approach. This paper introduces such a mathematical model and demonstrates how portfolio managers can create value for their clients using it.
\end{abstract}

Key words: portfolio management, hedge funds, alpha-beta separation, core-satellite portfolios, Islamic finance.

JEL Classification: G11, G15, F36

\section{Introduction}

This paper started with a practical problem - in the summer of 2013 the author was approached by a newly created hedge fund from Dubai for the development of investment strategies that both comply with Islamic finance and introduce some techniques of active portfolio management. It was a challenging task since short-selling, a practice commonly used by hedge funds to implement the long/short or market-neutral strategy, is prohibited under the principles of Shariah. Thus, the alpha-beta separation strategy was my suggestion with the overall portfolio being built in such a way it always complies with Islamic principles while sub-portfolios may deviate from them.

Several recent studies have been dedicated to Islamic finance. For instance, Patel (2008) in-vestigates the limitations that are posed by the principles of Shariah on the business models, industries and the permitted portfolio management techniques. Ismail and Tohirin

Corresponding author:

${ }^{1}$ International Marketing Manager, Global Spirits, Kiev.

Email: val.khokhlov@gmail.com
(2010) analyze the fundamentals of the Islamic law from the legal perspective and conclude that charging interest and using "unjust" financial practices are prohibited. Jawadi (2014) also notes that the principles of Shariah prevent from investing into some industries, such as alcohol, pork-related products, ammunition. Therefore, some stock screening should be implemented in order to be compliant with Islamic finance.

One of the approaches to the problem of creating a Shariah-compliant portfolio management strategy is alpha-beta separation. This approach was pioneered by Treynor and Black (1973) who suggested splitting the portfolio into two parts, the passively managed core and the actively managed satellite. The authors developed a mathematical model (the Treynor-Black model) that was aimed at the Sharpe ratio maximization, but it doesn't solve the problem we face with the Islamic finance compliance. Leibowitz and Bova (2005) developed a related "alpha core" approach that allows separation of alpha and beta on the portfolio level, 
however their research focused on adding alternative asset classes to the traditional portfolio and does not suit our purpose. A more relevant framework was suggested by Chin (2010) who developed an intuitive solution without providing a mathematical model under it.

The purpose of this paper is to develop a mathematical alpha-beta separation model that can be used in order to create a core-satellite portfolio structure that complies with the Islamic finance principles. We start with developing this model based on existing models of tracking error volatility (TEV) and mean-variance optimization (MVO). Then we outline our portfolio construction procedure and test the portfolio developed under these strategies. We conclude our paper with the findings we got during this research.

\section{Alpha-Beta Separation Model}

The key idea of alpha-beta separation, starting with Treynor-Black (1973), relates to splitting the portfolio into two parts, one of which (referred to as the core) is passively managed in order to track the benchmark, i.e. generate beta, and another is actively managed in order to add value by generating alpha. This idea is widely used by hedge funds, however it also can be used to overcome the limitations that Islamic finance poses on the portfolio management techniques. Let's start with the basic framework to illustrate this idea. The portfolio can be represented as a combination of the core and the satellite parts as follows:

$$
w_{i}=\lambda w_{i}^{a}+(1-\lambda) w_{i}^{c},
$$

where $w_{i}$ is the weight of $i$-th asset in the combined portfolio,

$\lambda$ is the weight of the actively managed (satellite) part of the portfolio,

$w_{i}^{a}$ is the weight of $i$-th asset in the actively managed (satellite) portfolio,

$w_{i}^{c}$ is the weight of $i$-th asset in the benchmark-tracking (core) portfolio.

In the simplest case we create two independent portfolios, both of which are managed according to its own investments policy. Ideally, the core portfolio can be built by replicating the benchmark or investing the entire amount into the benchmark-tracking ETF. However, in practice it may pose a significant problem, because the benchmark may not be directly investable or no corresponding ETFs may exist. In that case, the tracking portfolio may be created using one of the mathematical optimization models, for example by Roll (1992), Rudolf (1999), Jorion (2003). We will use the quadratic optimization model developed in Khokhlov (2011). In order to derive the optimal asset weights for the core portfolio we minimize the tracking error volatility (TEV):

$$
\omega^{2}=\operatorname{var}\left(r_{p}-r_{b}\right)=\operatorname{var}\left(\sum_{i=1}^{n} w_{i}^{c} r_{i}-r_{b}\right) \rightarrow \min ,
$$

where $₫$ is the TEV, which is the standard deviation of the tracking error,

$r_{p}, r_{b}, r_{i}$ are the expected returns on the portfolio, benchmark and $\mathrm{i}$-th asset respectively.

As demonstrated in Khokhlov (2011), formula (2) can be transformed into the objective function for a standard quadratic programming problem:

$$
\begin{aligned}
& \omega^{2}=\sum_{i, j=1}^{n} w_{i}^{c} w_{j}^{c} \sigma_{i j}-2 \sigma_{b}^{2} \sum_{i=1}^{n} w_{i}^{c} \beta_{i}+\sigma_{b}^{2} \rightarrow \min , \\
& \text { subject to constraints } \\
& \sum_{i=1}^{n} w_{i}^{c}=1, \\
& w_{i}^{c} \geq 0,
\end{aligned}
$$

where $w_{i}^{c}$ is the weight of $i$-th asset in the core portfolio (the optimization variable),

$\sigma_{i j}$ is the covariance between the returns of $i$-th and $j$-th assets,

$\sigma_{b}$ is the standard deviation of the benchmark,

$\beta_{i}$ is the beta of $i$-th asset with respect to the benchmark.

Long-only satellite portfolio. The satellite portfolio can be created by any absolute return strategy, ranging from the stock picking to the mean-variance optimization (MVO). We use the classic MVO technique by solving the Markowitz (1952) quadratic programming problem

$$
U=r_{p}^{a}-\frac{1}{r_{t}}\left(\sigma_{p}^{a}\right)^{2}=\sum_{i=1}^{n} w_{i}^{a} r_{i}-\frac{1}{r_{t}} \sum_{i, j=1}^{n} w_{i}^{a} w_{j}^{a} \sigma_{i j} \rightarrow \max ,
$$

subject to constraints

$$
\sum_{i=1}^{n} w_{i}^{a}=1 \text {, }
$$$$
w_{i}^{a} \geq 0 \text {, }
$$

where $w_{i}^{a}$ is the weight of $i$-th asset in the satellite portfolio (the optimization variable),

$r_{t}$ is the risk tolerance (a subjective value that reflects the investor's risk aversion),

$r_{p}, r_{i}$ are the expected returns on the satellite portfolio and $i$-th asset respectively,

$\sigma_{p}^{a}$ is the standard deviation of the satellite portfolio,

$\sigma_{i j}$ is the covariance between the returns of $i$-th and $j$-th assets.

Satellite portfolio with short positions. As we can see, problems (3) $-(5)$ and (6) $-(8 a)$ are two quadratic programming problems, each of them can be solved independently, and both solutions comply with the Islamic finance limitations. That presents a viable scenario, however from the perspective of the entire portfolio we can try to reach a better combined outcome. Note that constraint (8a) in fact doesn't represent an actual limitation, since we are only required to restrict the short selling on the combined portfolio basis, and as far as we have some allocation to $i$-th asset in the core portfolio we can have a negative weight in the satellite portfolio:

$$
\lambda w_{i}^{a}+(1-\lambda) w_{i}^{c} \geq 0,
$$


therefore we can relax the constraint ( $8 \mathrm{a}$ ) as follows:

$$
w_{i}^{a} \geq-\frac{1-\lambda}{\lambda} w_{i}^{c} \text {. }
$$

It should be noted that in the prober alpha-generating case the model (6)-(8b) should be superior to the model (6) $-(8 a)$, because it expands the feasible solutions set. However, in practice the model largely depends on the ability to forecast the expected returns, and failure to do so leads to the negative-alpha solution, in that case the model $(6)-(8 b)$ can potentially lead to a greater value destruction.

Finally, another practical trick that can be added to the portfolio management strategy relates to the rebalancing. As the times passes the asset prices change, so the actual asset weights in the portfolio deviate from the optimal solutions generated at some date in the past. Moreover, the optimal solution at the new date is not the same as it was before, so the manager needs to periodically solve problems (3)-(5) and (6)-(8) to derive the new optimal weights and rebalance the port-folio. However, frequent rebalancing may lead to the excess trading volume, and even to buying-selling the same asset over and over again. A practical trick mentioned above is smoothing, i.e. re-balancing only a part of the portfolio on each rebalancing date, for example at date $t$ the actual port-folio weights can be calculated as follows:

$$
r_{i}^{t}=(1-\delta) r_{i}^{*}+\delta r_{i}^{t-1},
$$

where $r_{i}^{t}, r_{i}^{t-1}$ are the $i$-th asset weights in the combined portfolio at dates $t$ and $(t-1)$ respectively,

$r_{i}^{*}$ is the weight calculated with (1) based on optimal solutions of (3)-(5) and (6)-(8),

$\delta$ is the smoothing factor, where $\delta \leq 0 \leq 1$ and $\delta=0$ means no smoothing.

\section{Portfolio Construction Procedure}

The inception date for the portfolio construction is September 1, 2013, and all the portfolios considered later are created at that date. It's assumed that the fund has been already invested by that date, and the initial investment is assumed to be $\$ 1,000,000$ (for our purposes we can assume that the results presented in this paper can be scaled to any reasonable fund size by multiplying them by the actual fund size in million U.S. dollars).

We consider 32 large-cap U.S. stocks that comply with the Islamic finance principles, notably the companies not involved in alcohol, tobacco, gambling, defense, as well as we exclude financial firms since they are likely to be involved into interest-based transactions. The resulting set consists of the following stocks, which are used to create the core portfolio: AAPL, AVP, BAX, BHI, BMY, CL, CVS, CVX, EMC, FDX, GOOG, HAL, HD, IBM, INTC, JNJ, LOW, MCD, MMM, MRK, NKE, PEP, PFE, PG, QCOM, ORCL, SBUX, TXN, UPS,
WBA, XOM. The satellite portfolio is created using a smaller set: AAPL, CVX, GOOG, JNJ, NKE, PEP, PFE, PG, UPS, and XOM. The benchmark is the Dow Jones Islamic Market U.S. index (^IMUS on Yahoo! Finance).

The core portfolio is created by solving problem (3) - (5) and the satellite portfolio is created by solving problems $(6)-(8 a)$ or $(6)-(8 b)$ with $r_{t}=0.2$, after that two parts are combined using formula (1). In our base care we use $\lambda=0.2$ in (1), and later we will investigate the impact of a different values of $\lambda$. A more sophisticated approach would be to adjust it dynamically as suggested in Caliman (2013). During subsequent rebalancing we consider both smoothing $(\delta-=0.5)$ and no smoothing cases, which results in four portfolios being considered:

- portfolio P0 - long-only satellite and no smoothing;

- portfolio P1 - long-only satellite and smoothing;

- portfolio P2 - satellite with short positions and no smoothing;

- portfolio P3 - satellite with short positions and smoothing.

The portfolios created as specified above are held during the pre-specified period ( 1 or 3 calendar months), after which the portfolio is rebalanced, i.e. the new target portfolio composition is determined by solving problems problem (3) $-(5)$ and $(6)-(8 a)$ or (6) $-(8 \mathrm{~b})$, for portfolios P1 and P3 the old and the new weights are combined using (9), and after that buy and sell transactions are per-formed in order to bring the portfolio composition in compliance with the new asset weights.

\section{Portfolio Management Results}

Portfolios P0-P3 with monthly rebalancing track the benchmark quite well during the first two years (September 2013 to August 2015) but start to deviate from the benchmark during the third year (see Figure 1). It seems that almost no alpha was generated during the initial years, and the more aggressive portfolios (P2 and P3) even destroyed some value, however during the final year they recovered, and started to dominate the less aggressive portfolios $\mathrm{P} 0$ and $\mathrm{P} 1$.

The portfolio management results for the portfolios with monthly rebalancing are summarized in Table 1 (annual risk-free rate was assumed to be $4 \%$ ). All the strategies presented in this paper resulted in significant amount of value added by portfolio management, with alpha ranging from $4.1 \%$ to $5.2 \%$. Moreover, most of the portfolios were less risky than the benchmark.

We can conclude that the satellite portfolio with short positions clearly makes sense when no smoothing is performed (P2 vs. P0 case), whereas in the smoothed case (P3 vs. P1) there was no additional gain in returns, only the volatility increased. The least risky portfolio turned out to be P1 (long-only satellite, smoothing), which has the lowest standard deviation and tracking error. The most risky portfolio that offered the highest 
reward to the risks taken was P2 (satellite with short positions, no smoothing).

Shifting from monthly to quarterly rebalancing leads to entirely different outcomes (see Figure 2). All the portfolios track the benchmark with much lower accuracy from the very beginning, and the less risky smoothed portfolios P1 and P3 tend to dominate portfolios with no smoothing until the final year. Therefore, strategies developed in this paper are much more accurate with frequent rebalancing.
The portfolio management results for the portfolios with quarterly rebalancing are summarized in Table 2 . As before, all the strategies presented in this paper do create value, and the alphas range from $4.0 \%$ to $5.7 \%$. However, only portfolios $\mathrm{P} 0$ and $\mathrm{P} 1$ are less risky than the benchmark, while portfolio P2 and P3 expose investors to higher volatility without offsetting it by higher re-turns.

We can conclude, therefore, that quarterly rebalancing doesn't make much sense for the satellite portfolio

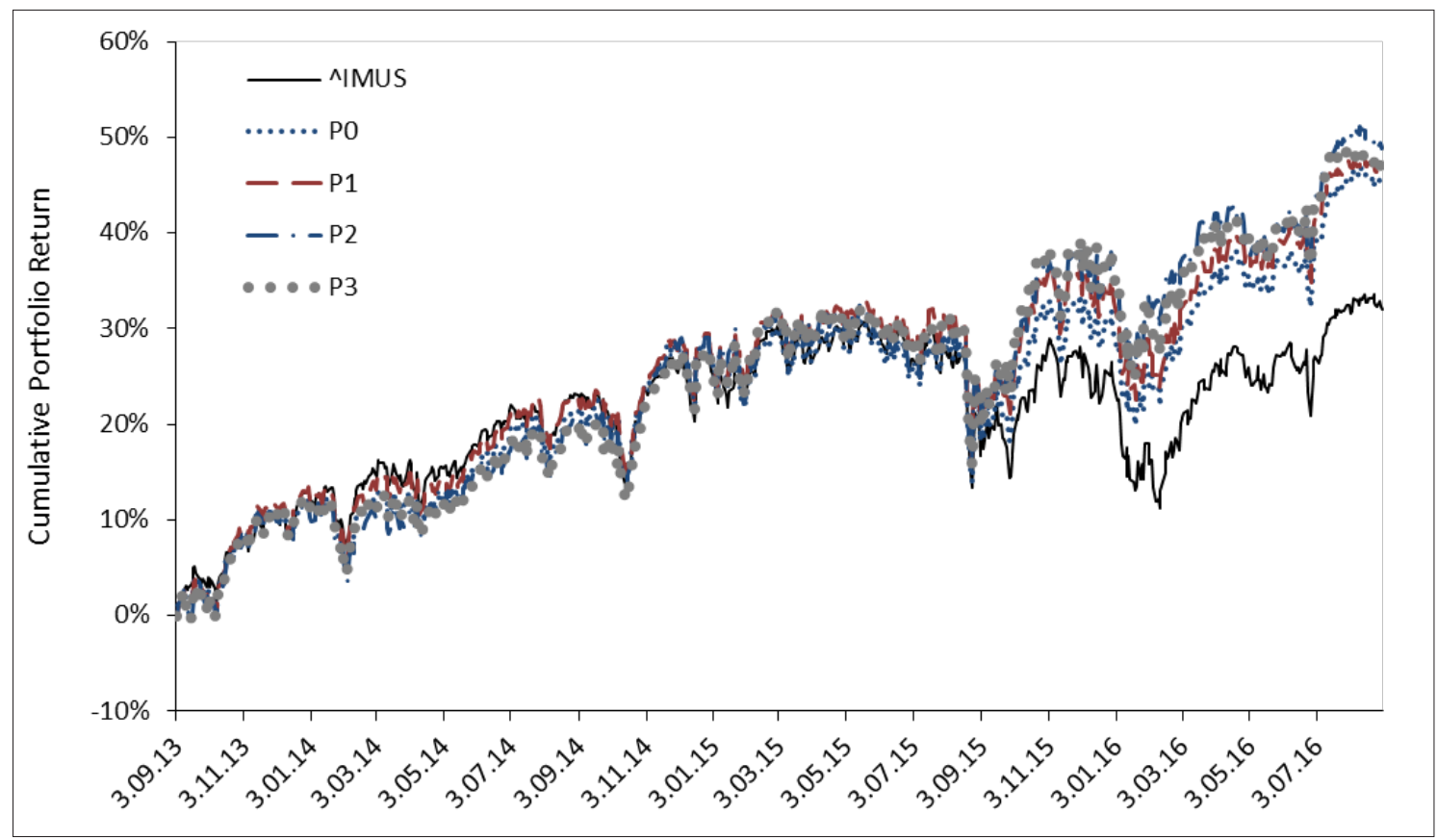

Fig. 1. Portfolio dynamics for the portfolios with monthly rebalancing

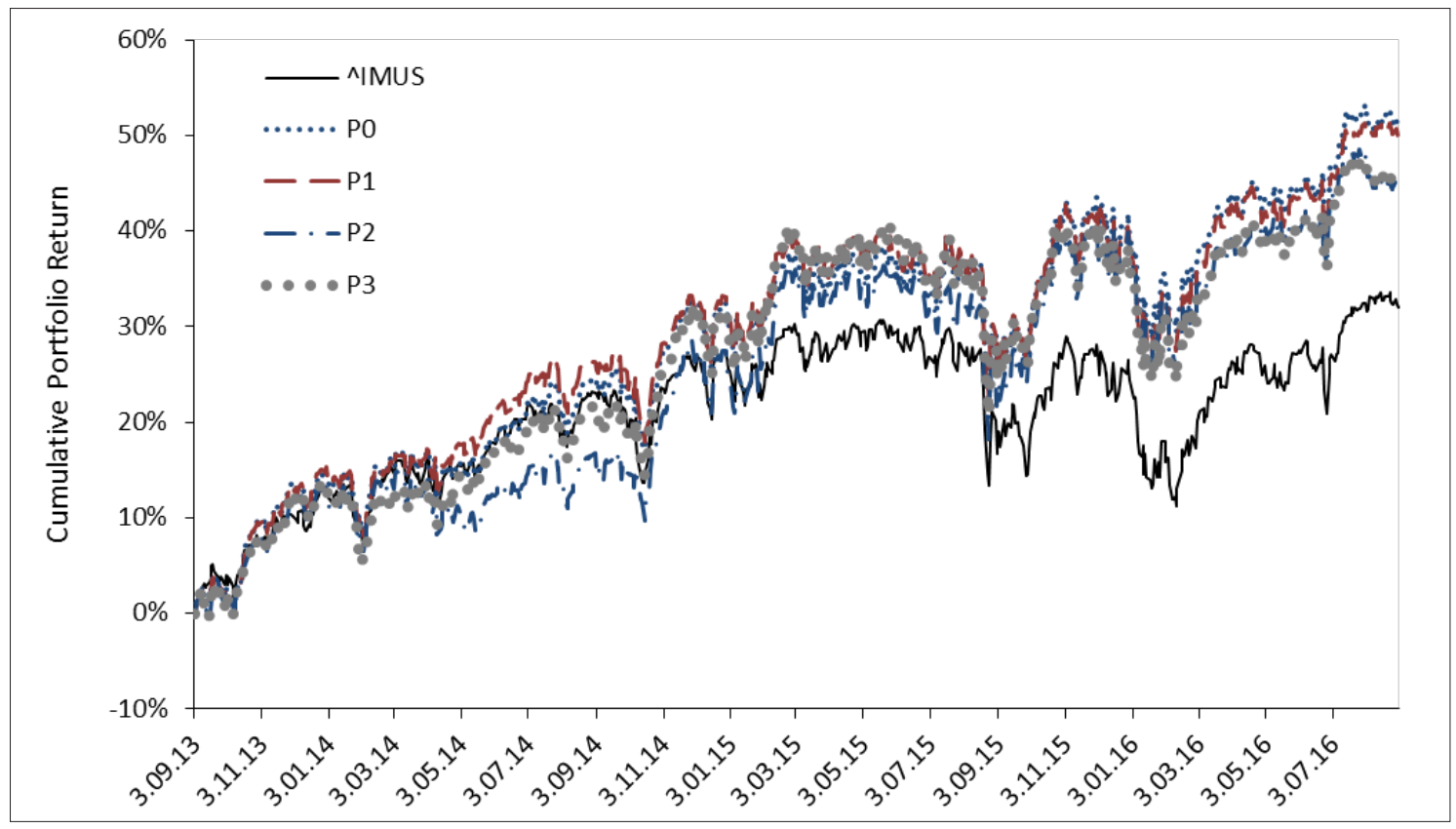

Fig. 2. Portfolio dynamics for the portfolios with quarterly rebalancing 
Table 1

Portfolio results for the portfolios with monthly rebalancing

\begin{tabular}{|l|c|c|c|c|c|}
\hline \multicolumn{1}{|c|}{ Portfolio } & $\wedge$ & P0 & P1 & P2 & P3 \\
\hline Total return, annualized & $9.57 \%$ & $13.37 \%$ & $13.68 \%$ & $14.29 \%$ & $13.68 \%$ \\
\hline Standard deviation & $13.63 \%$ & $13.61 \%$ & $13.39 \%$ & $14.02 \%$ & $13.61 \%$ \\
\hline Alpha & $0.00 \%$ & $4.14 \%$ & $4.48 \%$ & $5.22 \%$ & $4.60 \%$ \\
\hline Beta & 1.0000 & 0.9380 & 0.9345 & 0.9100 & 0.9133 \\
\hline Sharpe ratio & 0.4084 & 0.6880 & 0.7229 & 0.7339 & 0.7113 \\
\hline $\begin{array}{l}\text { Tracking error (TEV), } \\
\text { annualized }\end{array}$ & $0.00 \%$ & $4.35 \%$ & $3.77 \%$ & $6.38 \%$ & $5.32 \%$ \\
\hline
\end{tabular}

(Source: calculated by the author)

Table 2

Portfolio results for the portfolios with quarterly rebalancing

\begin{tabular}{|l|c|c|c|c|c|}
\hline \multicolumn{1}{|c|}{ Portfolio } & $\wedge$ IMUS & P0 & P1 & P2 & P3 \\
\hline Total return, annualized & $9.57 \%$ & $14.88 \%$ & $14.57 \%$ & $13.12 \%$ & $13.26 \%$ \\
\hline Standard deviation & $13.63 \%$ & $13.53 \%$ & $13.48 \%$ & $14.43 \%$ & $14.02 \%$ \\
\hline Alpha & $0.00 \%$ & $5.70 \%$ & $5.37 \%$ & $3.96 \%$ & $4.10 \%$ \\
\hline Beta & 1.0000 & 0.9299 & 0.9345 & 0.9271 & 0.9278 \\
\hline Sharpe ratio & 0.4084 & 0.8043 & 0.7838 & 0.6321 & 0.6605 \\
\hline $\begin{array}{l}\text { Tracking error (TEV), } \\
\text { annualized }\end{array}$ & $0.00 \%$ & $4.43 \%$ & $4.09 \%$ & $6.78 \%$ & $5.83 \%$ \\
\hline
\end{tabular}

(Source: calculated by the author)

Table 3

Portfolio results for various smoothing parameters

\begin{tabular}{|l|c|c|c|c|c|c|c|c|c|c|c|c|c|}
\hline & \multicolumn{9}{|c|}{ No short positions in the satellite } & \multicolumn{7}{c|}{ Short positions in the satellite allowed } \\
\hline Smoothing, $\delta$ & 0 & 0.1 & 0.2 & 0.3 & 0.4 & 0.5 & 0 & 0.1 & 0.2 & 0.3 & 0.4 & 0.5 \\
\hline & \multicolumn{8}{|c|}{ Panel A. Monthly rebalancing } \\
\hline Total return & $13.37 \%$ & $13.47 \%$ & $13.54 \%$ & $13.59 \%$ & $13.64 \%$ & $13.68 \%$ & $14.29 \%$ & $14.28 \%$ & $14.20 \%$ & $14.08 \%$ & $13.89 \%$ & $13.68 \%$ \\
\hline St. deviation & $13.61 \%$ & $13.56 \%$ & $13.51 \%$ & $13.46 \%$ & $13.42 \%$ & $13.39 \%$ & $14.02 \%$ & $13.91 \%$ & $13.82 \%$ & $13.74 \%$ & $13.67 \%$ & $13.61 \%$ \\
\hline Alpha & $4.14 \%$ & $4.25 \%$ & $4.33 \%$ & $4.38 \%$ & $4.43 \%$ & $4.48 \%$ & $5.22 \%$ & $5.21 \%$ & $5.13 \%$ & $5.00 \%$ & $4.82 \%$ & $4.60 \%$ \\
\hline Beta & 0.9380 & 0.9373 & 0.9365 & 0.9357 & 0.9350 & 0.9345 & 0.9100 & 0.9104 & 0.9109 & 0.9114 & 0.9121 & 0.9133 \\
\hline Sharpe ratio & 0.6880 & 0.6985 & 0.7064 & 0.7125 & 0.7181 & 0.7229 & 0.7339 & 0.7392 & 0.7385 & 0.7335 & 0.7237 & 0.7113 \\
\hline TEV & $4.35 \%$ & $4.20 \%$ & $4.07 \%$ & $3.96 \%$ & $3.86 \%$ & $3.77 \%$ & $6.38 \%$ & $6.12 \%$ & $5.90 \%$ & $5.69 \%$ & $5.50 \%$ & $5.32 \%$ \\
\hline & \multicolumn{8}{|c|}{ Panel B. Quarterly rebalancing } \\
\hline Total return & $14.88 \%$ & $14.86 \%$ & $14.81 \%$ & $14.74 \%$ & $14.74 \%$ & $14.57 \%$ & $13.12 \%$ & $13.26 \%$ & $13.30 \%$ & $13.29 \%$ & $13.27 \%$ & $13.26 \%$ \\
\hline St. deviation & $13.53 \%$ & $13.50 \%$ & $13.48 \%$ & $13.47 \%$ & $13.47 \%$ & $13.48 \%$ & $14.43 \%$ & $14.33 \%$ & $14.23 \%$ & $14.15 \%$ & $14.08 \%$ & $14.02 \%$ \\
\hline Alpha & $5.70 \%$ & $5.68 \%$ & $5.63 \%$ & $5.55 \%$ & $5.55 \%$ & $5.37 \%$ & $3.96 \%$ & $4.10 \%$ & $4.14 \%$ & $4.13 \%$ & $4.10 \%$ & $4.10 \%$ \\
\hline Beta & 0.9299 & 0.93 & 0.93038 & 0.93119 & 0.93119 & 0.9345 & 0.9271 & 0.9271 & 0.9270 & 0.9272 & 0.9274 & 0.9278 \\
\hline Sharpe ratio & 0.8043 & 0.8041 & 0.8016 & 0.7969 & 0.7969 & 0.7838 & 0.6321 & 0.6460 & 0.6534 & 0.6568 & 0.6583 & 0.6605 \\
\hline TEV & $4.43 \%$ & $4.35 \%$ & $4.27 \%$ & $4.20 \%$ & $4.20 \%$ & $4.09 \%$ & $6.78 \%$ & $6.56 \%$ & $6.35 \%$ & $6.16 \%$ & $5.98 \%$ & $5.83 \%$ \\
\hline
\end{tabular}

(Source: calculated by the author)

that includes short positions, and the simplest of our strategies - long-only satellite with no smoothing results in the best outcome.

Comparing portfolios with different rebalancing periods we can clearly see the different in tracking error that is introduced by including short positions in the satellite portfolio - it adds about $2 \%$ to the tracking error. Smoothing, on the other hand, always lowers the tracking error, and the most dramatic decrease is experience in case of the satellite with short positions. Therefore, we al-ways face the risk-reward dilemma - either shift towards the more aggressive active bets (which implies no smoothing and short positions in order to amplify the benefits from active management) or track benchmark more accurately (which benefits from lower portfolio turnover and discourages short positions).

\section{The Impact of the Tactical Choices}

So far we have considered the base case of our strategy $(\lambda=0.2)$ with two variants of smoothing $(\delta=0$ and $\delta=0.5)$. Those two parameters $-\lambda$ and $\delta-$ along with the risk tolerance $r_{t}$ in (6) and the frequency of rebalancing 
Table 4

Portfolio results for various satellite weights (monthly rebalancing)

\begin{tabular}{|l|c|c|c|c|c|c|c|c|c|c|c|c|}
\hline & \multicolumn{9}{|c|}{ No short positions in the satellite } & \multicolumn{7}{c|}{ Short positions in the satellite allowed } \\
\hline Weight, $\lambda$ & 0 & 0.03 & 0.05 & 0.1 & 0.2 & 0.3 & 0.03 & 0.05 & 0.1 & 0.2 & 0.3 \\
\hline & \multicolumn{8}{|c|}{ Panel A. No smoothing } \\
\hline Total return & $14.29 \%$ & $14.16 \%$ & $14.07 \%$ & $13.83 \%$ & $13.37 \%$ & $12.88 \%$ & $15.34 \%$ & $15.43 \%$ & $15.15 \%$ & $14.29 \%$ & $12.67 \%$ \\
\hline St. deviation & $13.66 \%$ & $13.62 \%$ & $13.60 \%$ & $13.57 \%$ & $13.61 \%$ & $13.80 \%$ & $13.55 \%$ & $13.58 \%$ & $13.72 \%$ & $14.02 \%$ & $14.47 \%$ \\
\hline Alpha & $4.97 \%$ & $4.85 \%$ & $4.77 \%$ & $4.56 \%$ & $4.14 \%$ & $3.71 \%$ & $6.12 \%$ & $6.25 \%$ & $6.02 \%$ & $5.22 \%$ & $3.65 \%$ \\
\hline Beta & 0.9558 & 0.9531 & 0.9513 & 0.9469 & 0.9380 & 0.9290 & 0.9381 & 0.9309 & 0.9210 & 0.9100 & 0.9015 \\
\hline Sharpe ratio & 0.7530 & 0.7456 & 0.7405 & 0.7248 & 0.6880 & 0.6436 & 0.8365 & 0.8421 & 0.8129 & 0.7338 & 0.5989 \\
\hline TEV & $3.67 \%$ & $3.65 \%$ & $3.66 \%$ & $3.78 \%$ & $4.35 \%$ & $5.23 \%$ & $4.15 \%$ & $4.53 \%$ & $5.31 \%$ & $6.38 \%$ & $7.53 \%$ \\
\hline & \multicolumn{7}{|c|}{ Panel B. Smoothing with factor 0.5} & & & \\
\hline Total return & $14.26 \%$ & $14.18 \%$ & $14.12 \%$ & $13.97 \%$ & $13.68 \%$ & $13.38 \%$ & $14.10 \%$ & $14.00 \%$ & $14.07 \%$ & $13.68 \%$ & $13.07 \%$ \\
\hline St. deviation & $13.47 \%$ & $13.43 \%$ & $13.41 \%$ & $13.38 \%$ & $13.39 \%$ & $13.49 \%$ & $13.35 \%$ & $13.35 \%$ & $13.42 \%$ & $13.61 \%$ & $13.89 \%$ \\
\hline Alpha & $4.99 \%$ & $4.91 \%$ & $4.86 \%$ & $4.73 \%$ & $4.48 \%$ & $4.21 \%$ & $4.89 \%$ & $4.82 \%$ & $4.95 \%$ & $4.60 \%$ & $4.03 \%$ \\
\hline Beta & 0.9480 & 0.9459 & 0.9446 & 0.9412 & 0.9345 & 0.9277 & 0.9355 & 0.9295 & 0.9211 & 0.9133 & 0.9068 \\
\hline Sharpe ratio & 0.7621 & 0.7578 & 0.7544 & 0.7450 & 0.7228 & 0.6951 & 0.7567 & 0.7487 & 0.7509 & 0.7112 & 0.6533 \\
\hline TEV & $3.33 \%$ & $3.31 \%$ & $3.31 \%$ & $3.39 \%$ & $3.77 \%$ & $4.40 \%$ & $3.56 \%$ & $3.87 \%$ & $4.47 \%$ & $5.32 \%$ & $6.18 \%$ \\
\hline
\end{tabular}

(Source: calculated by the author)

represent the tactical choices that could significantly affect the outcomes of our strategies. First, we will investigate the impact of smoothing using different values for $\delta$ ranging from 0 to 0.5 . As we can conclude from Table 3 , increasing $\delta$ may or may not result in better returns, however it always reduces the standard deviation and the tracking error. So, smoothing makes sense purely for the reduction of risk, and sometimes it may also enhance returns (which can be the case when active bets prove to be counterproductive).

Second, we will investigate the impact of $\lambda$, which determines the weight of the satellite in the total portfolio. As we can see from Table 4, with no short positions allowed in the satellite the impact on returns is linear and depends on the success of the active bets - if they are adding value the total return increases and vice versa. That can be explained by the fact that the total portfolio is a linear combination of the core and the satellite. However, it's not the case when short positions are allowed - since the negative weights in the satellite depend on the core allocations, the total portfolio becomes a non-linear combination. For instance, $\lambda=0.05$ is superior to other core-satellite combinations when no smoothing is allowed, whereas $\lambda=0.1$ generated the highest alpha with smoothing. Moreover, the risk profile is significantly nonlinear both for portfolios with short positions and without them. We can note that based on both absolute risk and the tracking error, the optimal risk-return combinations correspond to a relatively small allocation to the satellite ( $3 \%$ to $10 \%$ ) and quickly decline when the allocation to the satellite grows over $10 \%$.

\section{Conclusions}

The principles of Islamic finance pose severe limitations on the portfolio management techniques that are typically utilized by hedge funds. In this paper we show how some of these constraints can be relaxed if the portfolio is split into the core and the satellite parts, where the core portfolio tracks the benchmark and the satellite portfolio is actively managed to generate alpha. In this case the existing assets allocation in the core part can be used to offset some short positions in the active part. It allows, among others, to implement the beta-neutral strategy. We show how tracking error volatility minimization can be combined with the active management on practice and develop a comprehensive mathematical model for the portfolio management under this framework.

Our findings are based on managing several coresatellite Shariah-compliant portfolios on the investment horizon of three years (September 2013 to August 2016). All the portfolios created with our approach have delivered significant value and generated alphas from $4 \%$ to $5.7 \%$. The actual results substantially depend on the rebalancing frequency. With frequent (monthly) rebalancing we got the most accurate tracking of the benchmark and the lowest amount of risk. Moreover, active bets tend to create value on short horizons, so it's with the monthly rebalancing we were able to generate the highest alpha from the most aggressive portfolio (satellite includes short positions, no smoothing introduced). As our modeling has demonstrated, the best results are achieved when $3 \%$ to $10 \%$ of the portfolio is allocated to the satellite with active management, and the remaining $90 \%$ to $97 \%$ is managed to minimize the tracking error.

As we shift towards less frequent rebalancing, active bets start working worse. Even with quarterly rebalancing it seems that no additional value can be created by allowing for short positions in the satellite portfolio. So our findings show that it's better to refrain from the aggressive portfolio management and use a 
long-only satellite in case of less frequent rebalancing. Smoothing can be used to reduce the tracking error, and the decrease is more significant if the satellite contains short positions. However, smoothing should be used with care - it would also reduce benefits from the active bets if they were successful.

\section{References}

Caliman, T., D'Hondt, C., Petitjean, M. (2013). Determining an optimal multiplier in dynamic core-satellite strategies. Journal of Asset Management, volume 14, issue 4, p. $210-227$.

Chin, P.F. (2010). The Core-Satellite approach - The case for beta. InFinance, volume 124, issue 2, p. 30-32.

Ismail, A.G., Tohirin, A. (2010). Islamic law and finance. Humanomics, volume 26, issue 3, p. 178-199.

Jawadi, F., Jawadi, N., Louhichi, W. (2014). Conventional and Islamic stock price performance: An empirical investigation. International Economics, volume 137, p. 73-87.

Jorion, P. (2003). Portfolio Optimization with Tracking-Error Constraints. Financial Analysis Journal, volume 59, issue 5, p. 70-82.

Khokhlov, V.Y. (2011). Tracking Portfolio Optimization. Economic Bulletin of the National Mining University, volume 2, p. 140-144.

Leibowitz, M.L., Bova, A. (2005). Allocation Betas. Financial Analysts Journal, volume 61, issue 5, p. 70-82.

Markowitz, H. (1952). Portfolio Selection. The Journal of Finance, volume 7, issue 1, p. 77-91.

Patel, E. (2008). Fundamentals of Islamic Finance. Accountancy SA, Jun 2008, p. 41-42.

Roll, R. (1992). A Mean-Variance Analysis of Tracking Error. Journal of Portfolio Management, volume 18, issue 4, p. 13-22.

Rudolf, R.A., Wolter, H.-J., Zimmermann, H. (1999). Liner Model for Tracking Error Minimization. Journal of Banking \& Finance, volume 23, p. 85-103.

Treynor, J.L., Black, F. (1973). How to Use Security Analysis to Improve Portfolio Selection. The Journal of Business, volume 46, issue 1, p. 66-86.

\section{ВАЛЕНТИН ХОХЛОВ}

\section{ПОРТФЕЛЬНЫЕ СТРАТЕГИИ С АЛЬФА-БЕТА РАЗДЕЛЕНИЕМ НА ПРИМЕРЕ ИСЛАМСКИХ ФИНАНСОВ}

Аннотация. Целью статьи является разработка математической модели альфа-бета разделения, которая может использоваться для создания портфельных стратегий типа «ядро-спутник», соответствующих принципам исламских финансов. Методология. Используется методология создания портфеля «ядроспутник» и подход альфа-бета разделения, при этом ядро портфеля управляется по стратегии минимизации ошибки слежения, а спутник - по стратегии оптимизации доходности и риска. Результаты динамики созданных портфелей ясно показывают, что разделение альфа-бета привело к созданию существенной стоимости. Типичные значения альфа находятся в диапазоне от 4\% до 5.7\%. Наиболее агрессивные стратегии, которые допускают короткие позиции по активам в портфеле-спутнике, работают наилучшим образом при частой перебалансировке и выигрывают за счет активных ставок. Техника сглаживания, которая была предложена для уменьшения оборачиваемости портфеля и стабилизации его состава, работает лучше при менее эффективных активных ставках, особенно в случае нечастой перебалансировки. Наилучшее соотношение доходности и риска получено при небольшой (3-10\%) части всего портфеля, которая выделяется в спутник, и управлении оставшейся частью (90-97\%) в соответствии с минимизацией ошибки слежения. Практическое значение. Модель альфа-бета разделения, предложенная в этой статье, может использоваться для расширения арсенала инструментов управления портфелем хедж-фондов, которые работают в условиях жестких ограничений, например, в случае исламских финансов. Разработанные нами математические модели позволяют построить практическую реализацию концепции альфа-бета разделения. Значение/оригинальность. Хотя идея альфа-бета разделения существовала в практике управления портфелями хедж-фондов и ранее, не было разработано целостной математической модели, а ее реализация базировалась на интуитивном подходе. В этой статье предложена такая математическая модель и продемонстрировано, как с ее помощью портфельные менеджеры могут создавать стоимость для своих клиентов. 